Lexis Vol. XLIV (2) 2020: 699-744

\title{
Un texto teatral oculto de Juan Pablo Forner: la comedia de Los aduladores
}

\author{
Jesús Cañas Murillo \\ Universidad de Extremadura
}

\section{RESUMEN}

En este artículo se rescata del olvido una las escasas obras teatrales compuestas por Juan Pablo Forner en el siglo XVIII español que hemos conservado, pero de la cual no existían noticias en la actualidad. Se trata de una comedia, Los aduladores, que fue estrenada, póstuma, en Madrid, en el Teatro de la Cruz, en el año 1797. Se estudian diversos aspectos sobre la misma: su conservación en bibliotecas, la transmisión de su texto, su autoría, sus fuentes de composición, las circunstancias de su estreno madrileño, la compañía que se ocupó de su representación, su éxito entre los espectadores y su eco en la prensa de la época. Se reproduce el único artículo que le fue dedicado, con motivo de su estreno, en los periódicos del momento publicados en Madrid, un artículo que apareció impreso en el Memorial literario, en el que se comentaba muy favorablemente su montaje, y se resumía su argumento.

Palabras clave: historia literaria, siglo XVIII español, teatro, comedia neoclásica, Juan Pablo Forner 
A Hidden Theater Text, Written by Juan Pablo Forner: The Play of Los aduladores

\begin{abstract}
This article rescues from oblivion one of the few plays composed by Juan Pablo Forner in the Spanish Eighteenth Century that we have preserved, but of which there was no news at the present time. It is a comedy, Los aduladores, which was premiered posthumously in Madrid, at the Teatro de la Cruz, in 1797. Various aspects are studied about it: its preservation in libraries, the transmission of its text, its authorship, its sources of composition, the circumstances of its Madrid premiere, the company that took care of its performance, its success among the audience, its echo in the press of the time. It reproduces the only article that was dedicated to him, on the occasion of its premiere, in the newspapers of the time published in Madrid, an article that appeared in print in Memorial Literario, which commented very favourably on his staging, and summarised his argument. Keywords: Literary History, Spanish Eighteenth Century, Theatre, Neoclassical Comedy, Juan Pablo Forner
\end{abstract}

\title{
1. Juan Pablo Forner y el mundo del teatro
}

Es hecho ya suficientemente conocido el gran interés que el emeritense Juan Pablo Forner siempre manifestó, a lo largo de toda su vida, por las creaciones dramáticas, $y$, en general, por el mundo del teatro. Es una constante que queda perfectamente reflejada en toda su producción, en la cual los escritos teatrales y sobre el mundo del teatro ocupan una importante parcela.

El autor extremeño quiso dedicar al arte dramático parte de su obra de creación. Compuso, con cierta frecuencia, textos teatrales, encuadrables en diferentes géneros, en el teatro breve, como Introducción o Loa [...] para la apertura del teatro en Sevilla (Sevilla, 1795); en la comedia, como La escuela de la amistad o el Filósofo enamorado (publicada, primero en Valencia, por Joseph de Orga, en 1796, y, al año siguiente 1797, en Barcelona, en la Oficina de Pablo Nadal); en la tragedia, como las hoy desconocidas Motezuma 
y Francisco Pizarro; en los diálogos dramáticos, como el Dialogo entre un Escolar y un Sabio à la moda, (Diario de las Musas, no 4, 4 de diciembre de 1790, pp. 15-7, y n ${ }^{\circ}$, de 5 de diciembre de 1790, pp. 19-22), o el Diálogo entre D. Silvestre, D. Crisóstomo y D. Plácido. Precédelo un prólogo al público sevillano (¿1795-1796?).

Igualmente, en repetidas ocasiones, redactó escritos en los que analizaba el mundo de la farándula, y exponía sus opiniones sobre sobre diversos temas teatrales, como la situación del teatro en sus días, las normas que debían respetarse en la composición de piezas de esta índole, la licitud y moralidad de las comedias, la calidad de los autores y textos del periodo, las características y calidad de sus propias aportaciones al género... Así, podríamos recordar su Fe de erratas del Prólogo del Theatro Hespañol que ha publicado Don Vicente García de la Huerta (1786), obra en la que arremete contra, entre otros asuntos, la peculiar ortografía utilizada en el texto del zafrense; las Reflexiones sobre la lección Crítica que ba publicado Don Vicente García de la Huerta. Las escribia en vindicación de la buena memoria de Miguel de Cervantes Saavedra, Tomé Cecial, exescudero del Bachiller Sansón Carrasco. Las publica don Juan Pablo Forner (Madrid, Imprenta Real, 1786); el Discurso imparcial $y$ verdadero sobre el estado actual del teatro español (inserto en el número uno de La Espigadera, Madrid, Blas Román, 1790); la Carta del diario de Madrid de 28 de Abril impugnando la Comedia del Filósofo enamorado, a la que sigue una defensa de la expresada crítica por un Amigo del Autor de la Comedia (Cádiz, por D. Manuel Ximénez Carreño, 1795); la Apología del vulgo con relación a la poesía dramática, (ubicada, como prólogo, al frente de la impresión de La escuela de la amistad o el Filósofo enamorado, 1796); la Continuación de la Carta del Autor de la comedia del Filósofo enamorado publicada en el Diario de Cádiz de 13 de Mayo pasado de este año en respuesta a la de D. Hugo Imparcial, que también se publicó en el Diario de 28 de Abril (Cádiz, Por D. Antonio Murguía, 1796); la Respuesta á los "Desengaños útiles y avisos importantes del Literato de Ecija"; la Carta dirigida á un vecino de Cádiz sobre la otra del L. J. A. C. un Literato sevillano con el título de la "La Loa", restituída 
á su primitibo ser. Su autor Rosauro de Safo, con una Epistola de Leandro Misono en nombre del Literato sevillano; la Respuesta del cura de Mairenilla la Taconera á la Carta de Juan Perote, sacristán de Armencilla, su fecha en Cádiz á 19 de Marzo de 1796. Publicada en la misma Ciudad á 23 de Mayo del propio año (Cádiz, Antonio Murguia, 1796); la Carta de M. V. Marcial a Don Manuel Fermin Laviano (Colección de obras manuscritas de la BNE, tomo III, pp. 24-35); la Respuesta á los "Desengaños útiles y avisos importantes del Literato de Ecija"; la Carta en defensa de la comedia El Viejo y la Niña (Colección de obras manuscritas de la BNE, tomo VI, pp. 252-274); la Consulta que Don Juan Pablo Forner, como fiscal que era de la Audiencia de Sevilla, hizo al Consejo de Castilla sobre que debian representarse comedias en la ciudad del Puerto de Santa María, sin embargo de haberse opuesto á ello la real Audiencia y el Acuerdo (Madrid, Imprenta de Burgos, 1816); o las "Causas del mal gusto en la poesía” (Obras de Don Juan Pablo Forner, Fiscal que fué del estinguido Consejo de Castilla. Recogidas y ordenadas por Don Luis Villanueva, Madrid, Imprenta de la Amistad, Calle de Jardines n. 16,1844 , pp. 145-148).

No todas sus obras teatrales, o sobre el teatro, se han conservado en la actualidad. Hay partes de sus composiciones de esta índole de las que conocemos su existencia, pero desconocemos sus textos concretos, algunos por completo, otros en su integridad, ya que solo hemos conservado fragmentos de los mismos, a veces gracias a que el propio Forner los copió en otros escritos de su producción. Es el caso de un fragmento de Las Vestales, la escena I de su Acto III, reproducida por su creador en sus Discursos filosóficos sobre el hombre ${ }^{1}$. De otros solo resta memoria de su título. Así, de las ya citadas tragedias Motezuma y Francisco Pizarro; o de las comedias Los falsos filósofos, El ateísta y La vanidad castigada. De otros conservamos descripciones de su contenido, como La cautiva española, comentada por el emeritense en una obra suya que le dedica,

\footnotetext{
Conocemos la escena I de su Acto III, por ser incluida por el dramaturgo en las "Ilustraciones” al segundo de sus Discursos filosóficos sobre el hombre (Forner 1787).
} 
una carta cuyo destinatario es el censor de la pieza, Ignacio López de Ayala, que, con su informe negativo, impidió su estreno en las tablas: Carta de don Juan Pablo Forner [...] a Don Ignacio López de Ayala [...] sobre haberle desaprobado su drama intitulado La Cautiva española (Forner 1784 , VI: 276-316).

En el presente trabajo nos vamos a ocupar de una obra que no suele figurar en la relación de los escritos dramáticos de Forner, y ni siquiera ha sido, en la mayoría de los casos, incluida en las listas de las piezas, conservadas o no, que el emeritense legó, como aportación, a la historia de la literatura española, europea y universal. Se trata de una comedia que llegó a ser conocida en su momento, en los años de la Ilustración, y que gozó en gran éxito y predicamento en sus días, aunque en ellos no fuese dada a conocer con el nombre de su creador. Se trata de un texto que se estrenó con fortuna en el siglo XVIII, —en el Teatro madrileño de la Cruz, en concreto-, en el año 1797. Nos referimos a una pieza breve, que fue identificada por su autor con el nombre de Los aduladores, título con el que pasó a la posteridad sin ser habitualmente asociada a su creador extremeño, especialmente en los años posteriores a la Ilustración, en los que la pieza ha sido desconocida y, habitual y generalmente, ignorada.

\section{Los aduladores en la cartelera madrileña de la Ilustración}

\subsection{Autoría y fuentes}

Los aduladores es un texto que en la historiografía literaria anterior a la segunda mitad del siglo XX no suele ser mencionado, y, mucho menos, asociado a la persona y a la producción literaria de Juan Pablo Forner. En los últimos tiempos solo lo hemos visto citado en dos importantes trabajos dedicados al teatro dieciochista, a las creaciones dramáticas de la Ilustración. Se trata de la Cartelera teatral madrileña del siglo XVIII (1708-1808), de René Andioc y Mireille Coulon (2008), y del Catálogo de Autores Teatrales del Siglo XVIII, de Jerónimo Herrera Navarro (1993).

René Andioc y Mireille Coulon, en el tomo segundo de su Cartelera, citan Los aduladores como obra estrenada, el 24 de julio de 
1797, en el Teatro de la Cruz, y repuesta, en el Teatro de los Caños del Peral, el 11 de febrero de 1806. Como género suyo indica que es una "pieza moral” en un acto. Explican que es una traducción de Destouches, aunque en la nota correspondiente aclara que esta consideración del texto como traducción se debe a Juan Antonio Ríos Carratalá y que tal afirmación necesita aclaraciones y matizaciones: "Según J. A. Ríos Carratalá, "Destouches en España», Cuad. de traducción e interpretación, 8/9, E.U.T.I., Barcelona, 1987, p. 258, n. 2. El Diario la atribuyó al autor de El Filósofo enamorado, esto es Forner (?); debe de ser un lapsus por El filósofo casado, de Destouches. El Mem. Lit. de sept. 1797, pp. 430-431, no menciona al autor” (Andioc y Coulon 2008, II, 616, y nota en 898).

Jerónimo Herrera Navarro, en su Catálogo de Autores Teatrales del Siglo XVIII, sin incluir ningún tipo de aclaración ni justificación, al realizar la relación de las obras dramáticas compuestas por Juan Pablo Forner, inserta, directamente, en la misma Los aduladores como creación del emeritense, indicando que se trata de una "Pieza moral en un acto", y que fue "Representada en el Teatro del Príncipe en septiembre de 1797” (1993: 188), lo cual es erróneo, como más adelante comprobaremos, pero explicable, tal vez, por haber consultado la crítica al montaje incluida en el Memorial Literario, y de la que, con posterioridad, nos ocuparemos.

No es extraño que encontremos en el trabajo de Jerónimo Herrera Navarro la atribución de la autoría de Los aduladores a Juan Pablo Forner. En realidad, tal adscripción de esta comedia a la creación dramática de este compositor tiene un carácter más antiguo. Procede de la propia época en la que le tocó vivir al escritor extremeño, y en la que se produjo la configuración y difusión de toda su producción, de los años de la Ilustración. Y, en concreto, la hallamos en uno de los periódicos de ese momento, que se hizo eco de su estreno y de los días en los que permaneció en cartel, o en los que, con posterioridad, fue repuesta sobre las tablas. Nos referimos al Diario de Madrid. 
El Diario de Madrid inició su publicación, con este título², el 1 de febrero de 1788, y acudió, con bastante regularidad, a su cita diaria con sus lectores hasta el 31 de diciembre de 1814, fecha en la que apareció su último número ${ }^{3}$. Constaba de cuatro páginas, en la última de las cuales aparecía con relativa frecuencia y regularidad una sección titulada "Teatros”. En esta se incluía información sobre los espectáculos que eran montados en los tres grandes locales teatrales públicos existentes en el Madrid del momento, Los Caños del Peral, La Cruz y El Príncipe, como es bien conocido. En ese lugar se pueden encontrar datos sobre las obras dramáticas de Juan Pablo Forner que subieron a la escena y pudieron ser presenciadas por el público en la Villa española convertida, desde Felipe II, en la sede de la Corte. En ese lugar (Diario de Madrid del lunes 24 julio de 1797, núm. 305, 876), se recoge el estreno, el día 24 de julio de 1797, de Los aduladores, en el Teatro de la Cruz, en una función compleja, de la que después nos ocuparemos. De su autor no se recoge el nombre, pero se indica, como reclamo para el auditorio, que la pieza ha sido compuesta por "el mismo ingenio que compuso el Filósofo Enamorado", obra de Forner, que obtuvo un gran éxito en años anteriores, que se mantuvo mucho tiempo en cartel, y que fue objeto de diversas reposiciones en las tablas, en diferentes teatros madrileños, como mostraremos en otro trabajo que actualmente tenemos en preparación. Tal atribución al extremeño, identificado siempre como "el mismo ingenio que compuso el Filósofo Enamorado", se encuentra en todos los números del Diario de Madrid en los que se menciona el montaje de la obra, hasta la sustitución de la misma, en las tablas, por otro texto distinto de diferente compositor.

\footnotetext{
2 Primero recibió el título de Diario Noticioso, Curioso, Erudito, Comercial, Público y Económico, con el que fue fundado, el 1 de febrero de 1758, por Francisco Mariano Nipho, también, después, su director (Sáiz 1990a).

3 Un nuevo periódico titulado Diario de Madrid, comenzó a publicarse el 1 de enero de 1825, en los inicios de la conocida como Década Ominosa (1824-1833), aunque, a los tres meses de su existencia, sufrió un cambio de cabecera, siendo identificado como Diario de avisos de Madrid, si bien, desde el mes de febrero 1836, recuperó su primitivo nombre de Diario de Madrid. A finales de 1918 concluyó la publicación de este periódico.
} 
El problema que puede ser planteado es si puede darse por fiable la atribución de Los aduladores a Juan Pablo Forner hecha por el Diario de Madrid. Como comprobamos antes, René Andioc y Mireille Coulon la consideran un error, pues, piensan, al ser — dan por cierto- una traducción de Destouches, seguramente el diarista encargado de la sección de teatros se equivocó al citar el título de la obra conocida, que es, según él, del mismo creador de la que ahora puede verse en la escena madrileña: "El Diario la atribuyó al autor de El Filósofo enamorado, esto es Forner (?); debe de ser un lapsus por El filósofo casado, de Destouches" (2008, II: 898, nota A.20). No obstante, para nosotros, la defensa de la autoría de Forner es perfectamente plausible y verosímil. La redacción de la misma es, sin duda, parangonable a la que hallamos en otros textos dramáticos compuestos por el escritor emeritense. Los puntos de contacto de su argumento con el otorgado a El Filósofo enamorado son notables y detectables en la simple lectura de esas dos comedias. La coincidencia ideológica entre ambas es clara también, con su defensa de la libertad de la mujer en la elección de pareja, hecha de forma similar en las mismas. Los recursos que se utilizan en la composición de las dos obras son, igualmente, parecidos, con unos enredos que tienen evidentes puntos de contacto. El trazado de los personajes y su construcción muestran, también, similitudes, como podremos mostrar, más detenida y pormenorizadamente, en el libro que actualmente preparamos la profesora de la Universidad de Sevilla Piedad Bolaños Donoso y yo mismo, en el que pretendemos estudiar y editar toda la obra dramática, conservada y que podamos rescatar del olvido, o de las bibliotecas y archivos pertinentes, de Juan Pablo Forner.

No solamente razones de composición avalan la atribución de Los aduladores al creador extremeño que nos ocupa. De la discutible relación de la pieza con el teatro de Destouches después nos ocuparemos. Hay motivos externos, históricos, que nos llevan a otorgar verosimilitud a las afirmaciones incluidas en el Diario de Madrid. En primer lugar, se trata de un periódico que suele incluir noticias suficientemente contrastadas en sus páginas, por lo que 
sus lectores otorgaban verosimilitud a las informaciones que en él aparecían. Además, el Diario se publica en la misma época de composición de Los aduladores, e incluye la noticia de su estreno en la misma fecha en la que se produce este, sin tiempo para que la distancia distorsione o enmascare la verdad. Cabe presuponer, pues, que el redactor de la noticia debía de estar bien informado de la actualidad de la Villa de Madrid en esos años. Era, entonces, esa su dedicación y su obligación profesional. Es extraño, pues, que vaya a cometer errores de atribución con un autor, que, por esos años, era bien conocido; que, por entonces, ya estaba ligado a la villa de Madrid, desde 1796, —año en el que se trasladó a la Corte al ser nombrado, como ascenso, Fiscal del Consejo de Castilla-; que era famoso en los ambientes literarios y culturales, —que, sin duda, le eran muy familiares al periodista autor de la afirmación-, y que había sido en vida —falleció en la capital, el 16 de marzo de 1797, antes del estreno de Los aduladores - temido como polemista, lo cual le había otorgado notoriedad pública y fama; y que había sido elegido, en el mismo 1797, Presidente de la Academia del Derecho Español, — sita en Madrid, y actualmente conocida como Real Academia de Jurisprudencia y Legislación-, lo cual era sabido en los ambientes informados del momento, en los que, con seguridad, se movería con familiaridad el redactor de la sección de teatro del Diario. Ante ello, es verosímil que el diarista no hiciese, sobre este particular, afirmaciones a la ligera, sino afirmaciones resultantes de una captación de noticias tomadas de fuentes fidedignas. Ante todo ello, la atribución de Los aduladores a Forner resulta, por este camino, por esta vía, por estos motivos, por esta fuente, digna de crédito, digna de ser, muy en serio, tomada en consideración. Por otro lado, nadie ha presentado razones, o indicios, de peso, sino únicamente circunstanciales, que anulen la credibilidad de la atribución transmitida por el Diario de Madrid.

Se ha insinuado que Los aduladores no es una obra de carácter original, sino una simple traducción, o adaptación, de un texto de Destouches. Lo hemos comprobado con anterioridad, al recordar como René Andioc y Mireille Coulon así lo afirman en su impres- 
cindible Cartelera teatral madrileña del siglo XVIII. Como vimos, allí, en una nota, también mencionada con anterioridad, se explica que la consideración de nuestro texto como traducción de Destouches se debe a Juan Antonio Ríos Carratalá (1987), quien la incluye en su artículo "Destouches en España (1700-1835)". Consultado este trabajo de Ríos, hemos podido comprobar que, en realidad, este investigador no hace un análisis detallado de la comedia; no la estudia como texto procedente de uno anterior de Destouches, indicando, y explicando, la existencia de semejanzas y diferencias entre los mismos; y que la mención de Los aduladores no figura en el cuerpo del estudio, sino simplemente en una nota (Ríos 1987: 258, nota 2), en la que se enumeran obras de Destouches traducidas, versionadas o adaptadas en la España de la Ilustración. Entre estas se incluye, efectivamente, Los aduladores, pero indicando que la consideración de traducción de Destouches se puede leer en el libro de Alda M. Coe (1935), Catálogo bibliográfico y crítico de las Comedias anunciadas en los periódicos de Madrid desde 1661 hasta 1819, y sin insertar ningún otro tipo de explicaciones. Efectivamente, en el Catálogo de Coe figura incluida nuestra comedia en dos ocasiones. Primero, en su página cinco, como obra anunciada en dos periódicos del siglo XVIII, el Memorial literario y el Diario de Madrid, en el cual, se indica, aparece atribuida al autor de El Filósofo enamorado, es decir, a Juan Pablo Forner, como vimos. Nada se explica aquí sobre la procedencia de su texto (Coe 1935: 5). Con posterioridad, se inserta en el "Índice de autores", en la entrada dedicada a "Destouches (Nericault)" ${ }^{4}$, en la cual se enumeran los títulos de las obras de este dramaturgo galo que fueron traducidas y montadas en España, y en tal enumeración Los aduladores encabeza la lista, aunque sin mayor tipo de explicaciones, y sin especificar el nombre que se ha otorgado a esta pieza en el supuesto original francés del que presuntamente procede. Ante todo ello, podemos comprobar que ningún dato, concreto y específico, avala la vinculación de la

\footnotetext{
4 Alda M. Coe (1935: 239-265) solo menciona a Destouches y las obras suyas traducidas o adaptadas en España en una página, la 246, de su trabajo.
} 
comedia que nos ocupa a un posible texto francés compuesto por Nericault Destouches. Ante la ausencia de mayores concreciones y especificaciones, y ante la falta de identificación del original del que pudiese proceder, hemos de concluir que, en el momento actual, no hay ningún motivo para dejar de insertar Los aduladores en la lista de creaciones teatrales originales que aportó la Ilustración española a la historia de nuestro arte dramático.

\subsection{Estreno y representaciones}

Tal y como queda reflejado en el Diario de Madrid, el estreno de Los aduladores tuvo lugar en la corte, en el Teatro de la Cruz, el lunes 24 de julio de 1797, algo más de tres meses después de que se produjese el fallecimiento de Juan Pablo Forner, acaecido, igualmente en Madrid, el 16 de marzo del mismo año de 1797 (Cañas 1987, 2011, 2018; Jiménez Salas 1944; Lopez 1999). Sustituyó sobre las tablas a una obra de Francisco de Rojas Zorrilla, Del rey abajo, ninguno, que se había representado hasta el domingo 23 de julio de 1797:

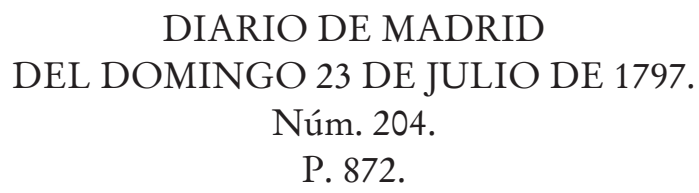

Teatros. Hoy á las 8 en punto, en el Coliseo de los Caños del Peral, por la Compañia Italiana, se representa la Opera seria intitulada: la Cora de Quito, Vestal del Templo del Sol, con el bayle del Pastor Fido.

En el de la calle del Principe, por la Compañia del Sr. Francisco Ramos, se representa el Guzman, el Bayle de la Alemanda, dos saynetes, y una tonadilla; á las 5. La entrada de antes de anoche fue de 2190. 
En el de la calle de la Cruz, por la Compañia del Sr. Luis Navarro, se representa la Comedia intitulada: del Rey abaxo ninguno, con saynete y una tonadilla; á las 5 .

\section{CON PRIVILEGIO REAL.}

En la Imprenta de Josef Franganillo, calle del Baño.

La compañía de Luis Navarro, que se había convertido, desde finales del siglo XVIII, en la titular del Teatro madrileño de la Cruz, -en concreto, por esos años, lo fue en las temporadas 1795-1796, 1796-1797, 1797-1798, 1798-1799, 1799-1800_, fue la encargada de llevar a las tablas Los aduladores y de facilitar su conocimiento y difusión entre los espectadores interesados. El texto, dada su corta extensión - pues solo contiene mil ciento setenta y nueve versos y su argumento había sido distribuido en un único acto-, formó parte, en ese espectáculo, de una función compleja que contenía varias y variadas piezas, unas dramáticas y otras musicales, como —además de nuestro texto ubicado en el segundo lugar en esa función- una obertura inicial, tal vez compuesta por Blas de Laserna una tonadilla, Las Damas del nuevo Cuño; la segunda parte del melodrama Armida y Reynaldo, de Vicente Ramírez de Arellano; otra tonadilla; el sainete Los cinco vecinos y, como complemento para hacer más atractivo el espectáculo, una boleras ${ }^{7}$ ejecutadas por el bailarín del Teatro de los Reales Sitios José González.

No conocemos, exactamente, el nombre de los cómicos que dieron cuerpo a cada uno de los personajes que aparecen en Los aduladores, pero sí el nombre de los actores que, en esa temporada,

\footnotetext{
5 Blas de Laserna trabajaba, como compositor, con la compañía de Luis Navarro en esa temporada (Barba 2015; la referencia a Laserna, 183).

6 Así es identificado el autor de esta obra en la Gazeta de Madrid, que alude a su montaje hecho por la compañía de Luis Navarro en el Teatro de la Cruz: “Armida y Reynaldo: primera y segunda parte escritas por D. Vicente Ramirez de Arellano, y representadas por la Compañía de Navarro. Se hallará en la Librería de Castillo, frente á S. Felipe el Real; y en el puesto de Cerro, calle de Alcalá" (Gazeta de Madrid del viernes 28 de Julio de 1797, núm. 60, "Madrid 28 de julio”, 676).

7 Una bolera es un "Aire musical popular español, cantable y bailable en compás ternario y de movimiento majestuoso” (Real Academia Española 1899).
} 
formaban parte de la compañía de Luis Navarro y, por lo tanto, que se repartieron los papeles. Se trataba de, —además del ya mencionado Luis Navarro, autor (director) de la agrupación-, Joaquina Arteaga, Rita Luna, Manuel García, Antonio Pinto, Félix de Cubas, Lorenza Correa, Bernardo Gil, y Mariano Querol. Todas estas noticias se transmiten en el número del Diario de Madrid que se hace eco del estreno de la obra, el 305, correspondiente al lunes 24 de julio de 1797, al que antes nos referimos:

\section{DIARIO DE MADRID \\ DEL LUNES 24 JULIO DE 1797. \\ Núm, 305. \\ P. 876.}

\section{Teatros. Hoy no hay Opera.}

En el de la calle de la Cruz, por la Compañia del Sr. Luis Navarro, se representa una completa funcion teatral, compuesta de varias piezas, todas nuevas, cuyo órden será el siguiente. Despues de la Obertura con que dará principio la orqüestra; seguirá en un acto la Comedia intitulada los Aduladores: es del mismo ingenio que compuso el Filósofo Enamorado: concluida ésta, cantará una buena tonadilla á solo, titulada las Damas del nuevo Cuño, la Sra. Joaquina Arteaga: en seguida se representará por los Sres. Rita Luna, Manuel Garcia, Antonio Pinto, y Félix de Cubas, el Melodrama intitulado Armida y Reynaldo, segunda parte, escrito por D. Vicente Ramirez de Arellano: finalizada ésta, se cantará otra tonadilla por los Sres. Lorenza Correa, Bernardo Gil, y Mariano Querol: por fin de fiesta se executará el saynete intitulado los cinco Vecinos. Para que á esta plausible representacion no falte circunstancia que contribuya á hacerla mas vistosa y agradable, á mas del decoro de los Actores, y del Teatro, se han añadido unas Voleras, que baylará Josef Gonzalez, Baylarin del Teatro de los Reales Sitios, con el primor que es notorio: la Compañia espera merezca esta funcion las 
atenciones de un público tan benigno, especialmente la Sra. Rita Luna, en cuyo beneficio cede el producto de este dia; á las 8. La entrada de ayer tarde fue de 1520: la de antes de anoche en el del Principe fue de 2133, y la de ayer tarde de 2327.

La tonadilla que cantará la Sra. Arteaga, se hallará de venta unida con su primera parte de la ciencia currutaca, que se ha cantado ya, á la entrada del Coliseo, y en la Libreria que está frente al mismo Coliseo.

Armida y Reynaldo, primera y segunda parte; se hallará en la libreria de Castillo, frente á S. Felipe el Real, en la de Cerro, calle de Cedaceros, y en su puesto, calle de Alcalá.

\section{CON PRIVILEGIO REAL.}

En la Imprenta de Joseph Franganillo, calle del Baño.

2.3. La función de Los aduladores y su recepción por el auditorio

La acogida que tuvo Los aduladores en el Teatro de la Cruz de Madrid puede ser calificada, sin error, no solo de aceptable, sino de rotundamente buena. Los datos que nos proporciona el Diario de Madrid, sin duda, así lo corroboran.

La comedia, según se recoge en el Diario, se mantuvo continuamente en cartel durante trece jornadas. En concreto, se representó los días 24, 25, 26, 27, 28, 29, 30, 31 de julio, y los días 2, 3, 4, 5 y 6 de agosto de 1797, pues el 1 de agosto no hubo funciones en los locales teatrales madrileños. En todas esas jornadas, la función en la que su texto se insertaba no sufrió ningún tipo de cambios ni variaciones hasta el viernes 4 de agosto de 1797, fecha en la se modificó en final de la misma, eliminando las boleras que interpretaba Josef González, bailarín del Teatro de los Reales Sitios, como antes pudimos comprobar; y de tal modo se mantuvo hasta su retirada del cartel. Así lo recoge el número correspondiente del Diario de Madrid: 


\section{DIARIO DE MADRID \\ DEL VIERNES 4 DE AGOSTO DE 1797. \\ Núm. 216. \\ P. 920.}

En el de la calle de la Cruz, por la Compañia del Sr. Luis Navarro, se representa una completa funcion teatral, compuesta de varias piezas, todas nuevas, cuyo órden será el siguiente. Despues de la Obertura con que dará principio la orqüestra; seguirá en un acto la Comedia intitulada los Aduladores: es del mismo ingenio que compuso el Filósofo Enamorado: concluida ésta, cantará una buena tonadilla á solo, titulada las Damas del nuevo Cuño, la Sra. Joaquina Arteaga: en seguida se representará por los Sres. Rita Luna, Manuel Garcia, Antonio Pinto, y Félix de Cubas, el Melodrama intitulado Armida y Reynaldo, segunda parte, escrito por D. Vicente Ramirez de Arellano: finalizada ésta, se cantará otra tonadilla por los Sres. Lorenza Correa, Bernardo Gil, y Mariano Querol: por fin de fiesta se executará e1 saynete intitulado los cinco Vecinos; á las 7 1/2. La entrada de antes de anoche fué de 3498.

\section{CON PRIVILEGIO REAL.}

En la Imprenta de Joseph Franganillo, calle del Baño.

Revisados todos los números del Diario de Madrid aparecidos en el mes de agosto del 1797, en contra de la noticia que transmite el Memorial literario, y de la que más adelante nos ocuparemos, no se realizaron representaciones de Los aduladores en el Teatro del Príncipe de la Corte, tan solo en el Teatro de la Cruz.

En los días de representación el horario de inicio de las funciones también fue objeto de algunos cambios. El lunes 24 de julio el estreno se produjo a las ocho. Los días 25 y 26 el espectáculo comenzó a las cinco. Los días 27, 28 y 29, a las ocho. Los días 30 y 31, a las cinco. El día 1 de agosto el Teatro de la Cruz permaneció cerrado: 


\section{DIARIO DE MADRID \\ DEL MARTES 1 DE AGOSTO DE 1797. \\ Núm. 213 \\ P. 908.}

Teatros. Hoy no los hay segun costumbre.

CON PRIVILEGIO REAL

En la Imprenta de Joseph Franganillo, calle del Baño.

Los días 2, 3, 4 y 5 de agosto la función tuvo lugar a las siete y media. Y, por fin, el último día del montaje, el 6 de agosto de 1797, a las cinco de la tarde.

Retirado de escena el espectáculo del que formó parte la obra que nos ocupa, Los aduladores, el Teatro de la Cruz permaneció, durante tres días, el 7, 8 y 9 de agosto, sin aparecer en la sección de “Teatros” del Diario de Madrid, quizá por permanecer cerrado por entonces, al estar dedicada su compañía titular, la de Luis Navarro, a los necesarios, e imprescindibles, ensayos para poder presentar una nueva función a los posibles espectadores interesados. El siguiente estreno tuvo lugar el día 10 de agosto. En el cartel figuraban tres piezas dramáticas, la comedia Los amantes de Teruel, acompañada de un sainete y una tonadilla:

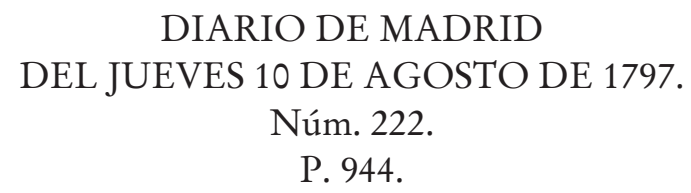

En el de la calle de la Cruz, por la Compañia del Sr. Luis Navarro, se representa la Comedia intitulada: los Amantes de Teruel; con sainete y una tonadilla; á las 5 .

El número de espectadores que quisieron acudir a presenciar las funciones del Teatro de la Cruz, _-durante el 
tiempo en el que permaneció en cartel el montaje que incluía Los aduladores -, a juzgar por la recaudación de taquilla que conocemos, fue alto. Hubo una media de ingreso de unos cinco mil reales. Los datos que proporciona sobre este particular el Diario de Madrid son los siguientes:

DíA

24 de julio

25 de julio

26 de julio

27 de julio

28 de julio

29 de julio

30 de julio

31 de julio

1 de agosto

2 de agosto

3 de agosto

4 de agosto

5 de agosto

6 de agosto
ENTRADA

7381

6265

5481

5811

5403

5724

5762

4254

Sin función

3498

3178

2522

2256

3190

La comedia Los aduladores dejó buen recuerdo en los espectadores de la era de la Ilustración, quienes quisieron conocerla los días en que se mantuvo sobre las tablas. Prueba de ello es que, pocos años después de que se efectuase su estreno, fue objeto de una reposición en la escena. Se efectuó esta en el año 1806, en el Teatro madrileño de los Caños del Peral.

En el Teatro de los Caños Los aduladores fue el texto encargado de sustituir, en las tablas, a una comedia popular titulada El carbonero de Londres, - que, seguramente, se trata de la así llamada compuesta por Antonio Valladares de Sotomayor-, y que daba cuerpo a una función también integrada por una tonadilla y un sainete, cuyos títulos no se especifican en las páginas del número correspondiente del Diario de Madrid: 


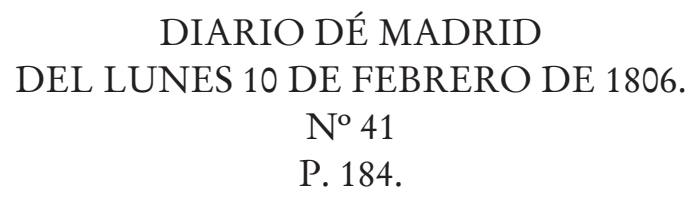

En el teatro de los Caños del Peral, á las 5 de la tarde, se representará por la Compañía destinada al teatro del Príncipe la comedia titulada El Carbonero de Londres, con tonadilla y sainete. La entrada de ayer tarde fué de 4.703 .

El nuevo montaje de Los aduladores estuvo a cargo de la compañía que trabajaba para el Teatro del Príncipe de Madrid. La función se estrenó el martes día 11 de febrero de 1806, a las cinco de la tarde. Formaban parte de esta, igualmente, tras el texto que nos ocupa, "una tonadilla á tres", cuyo título no se especifica en el Diario, y un sainete nuevo, La Fiesta de Toros de Juan Tuerto, en el cual se explica: "se lidiarán quatro de estos animales con la mayor naturalidad":

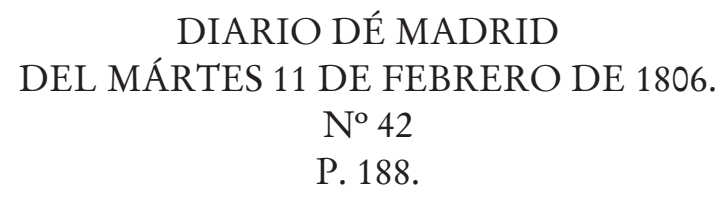

En el teatro de los Caños del Peral, á las 5 de la tarde, se executará por la Compañía destinada al teatro del Príncipe una divertida miscelánea de la forma siguiente: se dará principio con una pieza moral, en un acto, titulada Los Aduladores, seguirá una tonadilla á tres, y se dará fin con un gracioso saynete nuevo, nombrado La Fiesta de Toros de Juan Tuerto, en el que se lidiarán quatro de estos animales con la mayor naturalidad. La entrada de ayer tarde fué de 2.697 . 
El Diario de Madrid informa que la reposición de Los aduladores se mantuvo tres días en cartel, entre el martes y el jueves de la semana correspondiente, siempre en el Teatro de los Caños del Peral. En concreto, se representó los días 11, 12 y 13 de febrero de 1806. El viernes día 14 de febrero fue sustituida, en el mismo local, por una función múltiple, compleja, formada por las siguientes piezas:

\section{DIARIO DÉ MADRID \\ DEL VIERNES 14 DE FEBRERO DE 1806. \\ $\mathrm{N}^{\circ} 45$ \\ P. 204.}

En el teatro de los Caños del Peral, á las 5 de la tarde, se executará por la Compañía destinada al teatro del Principe la funcion siguiente; se dará principio con el saynete del Payo de la Carta, en el que cantará el Sr. Pedro Cubas las seguidillas del Gallinero, seguirá una tonadilla á tres titulada Los Maestros de la Raboso, y se dará fin con un gracioso saynete nuevo, nombrado La Fiesta de Toros de Juan Tuerto, en el que se lidiarán quatro de estos animales con la mayor naturalidad. La entrada de ayer tarde fué de 9.841 .

\section{CON REAL PRIVILEGIO}

La concurrencia de público, durante los días del montaje, fue animada, registrando el teatro cifras de recaudación muy superiores a las que obtuvo el último día, el lunes 10 de febrero de 1806, la obra, casi con seguridad de Valladares, que la precedió en escena, El Carbonero de Londres, la cual recolectó, con datos del Diario de Madrid, 2.697 reales, y algo superiores a las obtenidas, según la misma fuente, por la función que la sustituyó, que ingresó, el viernes día 14 de febrero de 1806, 9.174 reales, que bajaron, el sábado día 15 de febrero, a 9.148, y subieron, el domingo 16 de febrero, a 9.480, cifras todas inferiores, aunque a veces poco, a las registradas por las funciones de Los aduladores: 
DíA

11 de febrero

12 de febrero

13 de febrero
ENTRADA

12.554

11.743

9.841

El espectáculo, durante esos días 11, 12 y 13 de febrero de 1806, se inició siempre a las cinco de la tarde.

Revisados todos los números de Diario de Madrid correspondientes al mes febrero de 1806, y los correspondientes a la primera semana de marzo de 1806, no se detectan más noticias sobre Los aduladores.

Ante todos estos datos históricos que acabamos de rescatar, no podemos sino constatar, y concluir, que la comedia Los aduladores, tanto en su estreno en el Teatro de la Cruz, como en su reposición sobre las tablas en el Teatro de los Caños del Peral, cosechó un rotundo éxito en la escena, similar, aunque no tan amplio en el tiempo, - como estudiamos y demostramos en un trabajo mío que actualmente se encuentra en curso de publicación ${ }^{8}$-, al que había tenido, algunos años atrás, su predecesora, en el mismo aforo, el Teatro madrileño de la Cruz, La escuela de la amistad o El Filósofo enamorado, montada por primera vez, en ese local, por la Compañía de Eusebio Ribera, el día 28 de enero de 1795. Todo ello prueba la capacidad de conexión con sus espectadores, con su auditorio, que tuvieron, en sus días, y aún después del fallecimiento de su creador, las obras dramáticas compuestas por el emeritense Juan Pablo Forner.

3. Argumento y aportaciones de Los aduladores, según el Memorial literario

La comedia Los aduladores fue un texto que, hasta hoy, nunca ha sido difundido por medio de la imprenta. Carece de ediciones, ya desde los años de la Ilustración. Fue obra que permaneció, durante

\footnotetext{
8 Se trata del estudio "La Escuela de la amistad o El Filósofo enamorado en la prensa española de la Ilustración: estrenos y reposiciones”, de próxima impresión.
} 
mucho tiempo, prácticamente hasta nuestros días, olvidada, sin que se recordase su trayectoria histórica, su difusión, o el nombre de su autor. Quedó perdida, confinada en tres manuscritos que se guardaron en los archivos históricos conservados de los tres locales teatrales existentes, en el siglo XVIII, en la Villa y Corte de Madrid, donde permanecen en la actualidad, formando parte de la Biblioteca Histórica Municipal de la capital de España.

Están estos tres manuscritos relacionados con los montajes de los fue objeto la comedia en fechas próximas a su creación, y a los que con anterioridad nos hemos referido, detallándolos. Se trata de los apuntes, con signatura de la Biblioteca Municipal Tea 1-5-22, denominados A, que se halla relacionado con el montaje realizado en el Teatro madrileño de la Cruz, en el año 1797, montaje que supuso el estreno de la pieza; y de los apuntes que fueron denominados $\mathrm{B}$ y $\mathrm{C}$, que se vinculan con la reposición de la obra en el, también madrileño, Teatro de los Caños del Peral, en el año 1806. Así los describe Mercedes Agulló (1969-1977; 1978-1982; 1995: 248) en su libro La colección de teatro de la Biblioteca Municipal de Madrid:

87. “Los Aduladores. / En vn Acto. / Año de 97”. Ms. Letra del siglo XVIII. 1 cuadernillo. $21 \mathrm{~cm} .3$ ejemplares (1). Leg. $5-22$.

Primer verso: “--En fin, yo os ruego, señora...”

Ejemplar B:

"Los Aduladores. / Pieza en verso en un Acto".

[Añadido, con otra letra: "Dia 11 de Febrero de 1806”].

En la contraportada del ej. B:

"Personas

Don Juan - Galán Carretero

Doña Ysabel - Dama Prado

Don Ynocencio - Barba Rafael Pérez...”

Ejemplar C:

"Los Aduladores".

(1) 88. Los ejs. B y C con letra del siglo XIX. 
Debido a esta nula transmisión impresa, y a la escasa transmisión manuscrita, no es extraño que Los aduladores fuese obra ignorada por la crítica posterior, que no incluyó, por desconocimiento, referencias a la misma en las páginas que dedicó al teatro dieciochesco, y ni siquiera la mencionó como texto hoy perdido, pero de título conservado - como sucedió con otras obras del polemista emeritense-, entre las producciones debidas a la pluma del extremeño Juan Pablo Forner.

Por estas causas podemos considerar a Los aduladores como texto históricamente perdido y olvidado, pero hallado y rescatado en la actualidad. Su contenido y características se pueden dar, hoy en día, por desconocidos, dada su escasa, o nula presencia, en los comentarios, investigaciones y trabajos históricos que, a través de los tiempos, han sido dedicados por los estudiosos al teatro de la Ilustración.

En sus días, tampoco fueron abundantes las referencias a esta comedia que pudieron ser detectadas, en textos críticos, noticieros o eruditos. Su presencia en los periódicos del momento no es abundante. Queda, casi, reducida a la inclusión de su nombre en las carteleras de los espectáculos entonces montados en la escena madrileña, y de las que se hicieron eco determinadas publicaciones periódicas, como el, ya estudiado y comentado, Diario de Madrid.

No obstante esta situación desoladora para la pieza que hemos añadido a la lista de aportaciones que Juan Pablo Forner legó a la historia literaria y cultural de España, y a la historia literaria y cultural de la Ilustración europea y occidental en general, en el siglo XVIII, nuestro texto, en los momentos de su estreno, había conseguido llamar la atención y despertar el interés de un periódico de esos días, especializado en el mundillo literario y cultural de su tiempo. Se trató del Memorial Literario, Instructivo y Curioso de la Corte de Madrid.

El Memorial Literario se empezó a publicar en Madrid en el año 1784, y acudió a su cita con sus lectores hasta 1808, con algunas interrupciones (entre 1791-1793, y entre 1797 y 1801). Tenía primero periodicidad mensual, y, después, bimensual. Era impreso en 
la Imprenta Real. Sus fundadores fueron Pedro Trullent y Joaquín Ezquerra, Catedrático de Lengua Latina en los Reales Estudios de San Isidro de Madrid, siendo este último su principal redactor, aunque siempre contó con un buen plantel de colaboradores, la mayoría de los cuales prefirió no estampar su verdadero nombre en los trabajos que allí publicaban, utilizar pseudónimos, o dejar sus artículos sin firmar y presentarlos como anónimos. Obtuvo una muy buena acogida en los años de la Ilustración (Sáiz 1990b).

En el Memorial Literario, en concreto, en el número correspondiente al mes de septiembre de 1797, en las páginas 428-431, uno de sus colaboradores, sin firmar su trabajo, quiso comentar dos obras del espectáculo en el que fue incluida, en su primera subida a las tablas en Madrid, la comedia de Los aduladores. El primer texto del que se ocupa, entre las páginas 128 y 130, es Arminda y Reynaldo; el segundo, entre las páginas 430 y 431, Los aduladores. En su crítica teatral comete un grave error al afirmar que las dos piezas fueron escenificadas en el "Coliseo del Príncipe" (en la página 428), cuando, realmente, como vimos, el local teatral en el que se dieron a conocer ante el auditorio fue el Teatro de la Cruz, donde trabajaba la Compañía de Luis Navarro, que el redactor cita.

En su crítica teatral, el comentarista del Memorial quiso destacar el montaje del que había sido objeto Los aduladores sobre las tablas madrileñas. Quiso dar, a sus lectores, noticia del contenido que había recibido la obra, de su argumento. Quiso resaltar algunas características que su autor, en los momentos de su composición, le había otorgado, y que le parecen destacables y dignas de elogio. El juicio del articulista es esencialmente positivo, como comprobaremos después. Y ello es paralelo a la buena acogida que le habían tributado, en su estreno sobre las tablas del Teatro de la Cruz, los espectadores que acudieron a presenciarla, los primeros receptores que tuvo la comedia en los días de las Ilustración, en aquellas funciones de verano de los meses de julio y agosto del año 1797, a las que anteriormente nos hemos referido.

Esa fue, durante largo tiempo, e incluso hasta nuestros días, la única fuente de aproximación a Los aduladores a la que se podía 
acudir para obtener un cierto conocimiento de la pieza, para satisfacer la curiosidad del interesado en la literatura y la cultura dieciochescas. En la actualidad estamos elaborando, la Profesora Piedad Bolaños Donoso y yo mismo, como antes adelantamos, una investigación que pretende obtener como resultado un libro en el que se estudie, y recopile, toda la aportación que podamos localizar, y reproducir, del legado de Juan Pablo Forner al mundo del arte dramático, todas sus obras de creación, en este campo, que logremos conseguir, todos los escritos relacionados con el mundo del teatro que se hayan conservado, y que seamos capaces de identificar como obra del emeritense. Allí incluiremos el texto por primera vez editado de Los aduladores, que atribuimos, dados los razonables y verosímiles indicios y pruebas que así lo indican, al gran polemista y escritor extremeño del siglo XVIII. Sirva, mientras tanto, la transcripción, que a continuación se incluye, de la crítica del Memorial al montaje, en el Teatro de la Cruz, — no del Príncipe, como hemos antes advertido-, en el año 1797, de la obra que nos ha ocupado en el presente trabajo, como anticipo que permita efectuar, en cierto modo, a los interesados, una primera aproximación al contenido y a las características de la misma, antes de conocer su texto literal, cuya edición ya tenemos, Piedad Bolaños y yo, concluida, aunque aún nos quede mucho trabajo, y tiempo, para dar completamente por cerrada nuestra investigación. Sírvanos, también, a nosotros esa transcripción como colofón a este artículo que ahora terminamos de dar a conocer a nuestros formados, curiosos e interesados lectores. 


\title{
MEMORIAL LITERARIO. SETIEMBRE DE I797. PARTE II.
}

\author{
CONTINUACION \\ DEL MEMORIAL LITERARIO. \\ SETIEMBRE DE 1797. \\ PARTE SEGUNDA. \\ Pp. 430-431.
}

\section{${ }^{[428]}$ TEATROS. \\ COLISEO DEL PRINCIPE.}

\section{Compañia de Luis Navarro: piezas representadas en el mes de Agosto próximo anterior.}

${ }^{[430]}$ Los Aduladores. Comedia en un acto.

Argumento. D. Inocencio tenia una hija llamada Doña Isabel, á la qual queria casar con D. Braulio, hidalgo de provincia, hombre estrafalario, y encaprichado de su nobleza, pero no muy rico. Doña Isabel estaba enamorada de su primo D. Juan, pobre al presente; pero que litigaba con $\mathrm{D}$. Inocencio una quantiosa hacienda, con cuya esperanza pretendia este aumentar su riqueza unida con la de D. Braulio. No sabian los dos amantes cómo vencer á su padre y tio, para que se uniesen en recíproco lazo: válese D. Juan de D. Serapio y D. Antonio, hombres estremamente aduladores, que entraban freqüentemente en casa del padre, y le adulaban en todas las cosas, para que seducido de este modo, pudiesen comer á su mesa, y aun les facilitase sus acomodos. Prometen estos lisonjeramente servir á D. Juan; pero hacen lo contrario. Entre tanto viene el novio prometido D. Braulio, muestra su caracter ridículo, el qual desagrada enteramente 
[431]á Doña Isabel; y esta sin rodeos no solo le manifiesta su ninguna inclinacion, sino que le pide que se interponga con su padre para que la libre de una bestia extraordinaria, qual es el mismo novio.

Quédase consternado D. Braulio de semejante recibimiento y tratamiento: pone esto en noticia de D. Inocencio, el qual procura disuadirle como que era una chanza de su hija. Mientras esto pasa, gana D. Juan el pleyto, y D. Inocencio ve que entregando la hacienda á D. Juan queda pobre, y mucho mas al ver que $\mathrm{D}$. Braulio ya no quiere casarse con Doña Isabel faltando esta dote. D. Juan entonces ofrece todos sus haberes á D. Inocencio, y que casándose con su prima todo se quedará en casa. Conviene el padre, despidese D. Braulio, quedan despedidos y reprehendidos los aduladores, y D. Inocencio desengañado.

En esta comedia estan bien pintados los aduladores, bien expresada la sandez y avaricia del padre, y la ridiculez y orgullo del hidalgote, y en fin bien desempeñado el asunto. Es gracioso el pasage en que Doña Isabel á manera de Princesa acuitada pide al hidalgo quixote que la libre de aquel monstruo.

Referencias bibliográficas

Agulló y CoBo, Mercedes

1969-1977 “La Colección de Teatro de la Biblioteca Municipal de Madrid”. Revista de Literatura. XXXV. 71-72 (julio-diciembre 1969), pp. 169-213; XXXVII. 73-74 (enero- junio 1970), pp. 233274; XXXVIII. $75-76$ (julio-diciembre 1970), pp. 189-252; 1-2 (1977), pp. 179-231.

Agulló y Cobo, Mercedes

1978-1982 "La Colección de Teatro de la Biblioteca Municipal de Madrid". Revista de la Biblioteca, Archivo y Museo del Ayuntamiento de Madrid. 3. á época, núms. 3-4 (1978), pp. 125-187; núm. 5 (1979), pp. 191-218; núm. 6 (1980), pp. 129-190; núms. 
7-9 (1980), pp. 221-302; núms. 9-10 (1981), pp. 101-83; núms. 11-12 (1982), pp. 259-351.

Agulló y Cobo, Mercedes

1995 La colección de teatro de la Biblioteca Municipal de Madrid. Eds., Ascensión Aguerri Martínez y Purificación Castro Gómez. Madrid: Ayuntamiento de Madrid, Departamento de Archivos y Bibliotecas.

Andioc, René y Mireille Coulon

2008 Cartelera teatral madrileña del siglo XVIII (1708-1808). Madrid: Fundación Universitaria Española. Segunda edición corregida y aumentada. 2 Vols.

BARBA, Marina

2015 "Las orquestas de los Coliseos madrileños Príncipe y Cruz durante la segunda mitad del siglo XVIIII". Cuadernos dieciochistas. 16, 165-185. <https://doi.org/10.14201/cuadieci201516165185>

Bolaños Donoso, Piedad y Jesús Cañas Murillo

2010 Introducción o Loa para la apertura del teatro en Sevilla, de Juan Pablo Forner. [Seguida de la Anti-Loa para la cerradura del teatro de Sevilla, compuesta por D.J.P.F.F.D.C.D.L.A.R., y otros escritos contrarios]. Estudio y edición crítica. Sevilla: Universidad de Sevilla (Serie Literatura, 106).

Cañas Murillo, Jesús

1987 Juan Pablo Forner. Mérida: Editora Regional de Extremadura (Cuadernos Populares, 19).

Cañas Murillo, Jesús

2011 "Forner y Segarra, Juan Pablo. Mérida (Badajoz), 17.II.1756Madrid, 17. V.1797”. En Diccionario Biográfico Español. Director Científico, Gonzalo Anes y Álvarez de Castrillón. Académico coordinador, Quintín Aldea Vaquero. Director Técnico, Jaime Olmedo Ramos. Coordinación de la Edición, Icíar Gómez Hidalgo. Documentalista Responsable de la Comisión de Arte y Humanidades, Ángeles Lázaro Martínez. Vol. XX: De "Ferrero Llusiá" a "Furnius Iulianus". Madrid: Real Academia de la Historia, 477-481. 
Cañas Murillo, Jesús

2018 “Juan Pablo Forner y Segarra. Biografía”. En Diccionario Biográfico Español, edición electrónica. Madrid: Real Academia de la Historia. Consultado: 7 de mayo de 2018. <http://dbe. rah.es/biografias/9796/juan-pablo-forner-y-segarra>

Coe, Alda M.

1935 Catálogo bibliográfico y crítico de las Comedias anunciadas en los periódicos de Madrid desde 1661 hasta 1819. Baltimore: The John Hopkins Press.

Forner y Segarra, Juan Pablo

1784 Carta de don Juan Pablo Forner [...] a Don Ignacio López de Ayala [...] sobre haberle desaprobado su drama intitulado La Cautiva española, incluida en la Colección de obras manuscritas conservadas de la BNE, y regaladas por su autor, en su día, a Manuel Godoy, tomo VI, 276-316.

Forner y Segarra, Juan Pablo

1787 "Ilustraciones", “Al Discurso II”. En Discursos Filosóficos sobre el hombre, de Juan Pablo Forner. Madrid: Imprenta Real, 245-282. Las Vestales, 273-278.

Forner y Segarra, Juan Pablo

1795 Introducción o loa para la apertura del teatro de Sevilla, con una carta que le sirve de prólogo. Sevilla.

Forner y Segarra, Juan Pablo

$\mathrm{s} / \mathrm{f}(\mathrm{a}) \quad$ El ateísta. Comedia perdida.

Forner y Segarra, Juan Pablo

$\mathrm{s} / \mathrm{f}$ (b) La cautiva española. Comedia perdida. ${ }^{9}$

Forner y Segarra, Juan Pablo

$\mathrm{s} / \mathrm{f}(\mathrm{c}) \quad$ Los falsos filósofos. Comedia perdida.

\footnotetext{
9 Según Pedro Sainz y Rodríguez, de esta comedia, entre "Los manuscritos de Forner existen fragmentos" (1967: XXXIV). La noticia seguramente fue tomada del tomo II de la Biblioteca de traductores españoles de Menéndez y Pelayo, quien hablando de los papeles del emeritense conservados por Luis de Villanueva, afirma lo siguiente "Consérvanse, además, varias escenas de dos tragedias, Moctezuma y Francisco Pizarro, y de dos comedias, La Cautiva y La vanidad castigada” (1952: 90).
} 
Forner y Segarra, Juan Pablo

$\mathrm{s} / \mathrm{f}(\mathrm{d}) \quad$ Francisco Pizarro, Tragedia perdida. ${ }^{10}$

Forner y Segarra, Juan Pablo

$\mathrm{s} / \mathrm{f}(\mathrm{e}) \quad$ Motezuna. Tragedia perdida. ${ }^{11}$

Forner y Segarra, Juan Pablo

$\mathrm{s} / \mathrm{f}(\mathrm{f}) \quad$ La vanidad castigada. Comedia perdida. ${ }^{12}$

Forner y Segarra, Juan Pablo

$\mathrm{s} / \mathrm{f}(\mathrm{g}) \quad$ Las vestales. Tragedia perdida, compuesta, según su propio autor, "a la entrada de su juventud". La escena I de su Acto III fue conservada al ser incluida por el dramaturgo en las "Ilustraciones" al segundo de sus Discursos filosóficos sobre el hombre (Juan Pablo Forner: "Ilustraciones", "Al Discurso II”, en los Discursos Filosóficos sobre el hombre, de Juan Pablo Forner, Madrid: Imprenta Real, 1787, 245-282. Las Vestales, 273-278).

[Forner y Segarra, Juan Pablo]

1796a La escuela de la amistad ó El Filósofo enamorado. Comedia. Precede Apología del vulgo con relacion á la Poesía Dramática. Con licencia en Madrid: En la Imprenta de Fermín Villalpando.

[Forner y Segarra, Juan Pablo]

1796b Comedia Famosa. La escuela de la amistad, ó El Filósofo enamorado. Con Licencia: En Valencia: En la Imprenta de Joseph de Orga, donde se hallará, y en Madrid: en la Librería de Quiroga, calle de las Carretas.

\footnotetext{
10 Según Pedro Sainz y Rodríguez, de esta tragedia entre "Los manuscritos de Forner existen fragmentos" (1967, XXXIV), noticia seguramente tomada de Menéndez y Pelayo (1952: 90).

11 Según Pedro Sainz y Rodríguez, de esta tragedia, entre "Los manuscritos de Forner existen fragmentos” (1967, XXXIV), noticia seguramente tomada de Menéndez y Pelayo (1952: 90).

12 Según Pedro Sainz y Rodríguez, de esta comedia, entre "Los manuscritos de Forner existen fragmentos” (1967, XXXIV), noticia seguramente tomada de Menéndez y Pelayo (1952: 90).
} 
[Forner y Segarra, Juan Pablo]

1796c Respuesta [a la crítica de "Hugo Imparcial”] firmada por "El Autor del Filósofo enamorado", Diario de Cádiz, 13 de mayo de 1796, 173-188.

[Forner y Segarra, Juan Pablo]

1797a Comedia Nueva. La escuela de la amistad, ó El Filósofo enamorado. Barcelona: En la Oficina de Pablo Nadal, calle del Torrente de Junqueras. A costa de la Compañia. Y en dicha casa se hallarán otras de varios titulos escogidos.

[Forner y Segarra, Juan Pablo]

1797b Comedia Nueva. La escuela de la amistad, ó El Filósofo enamorado. Barcelona: En la Oficina de Pablo Nadal, calle del Torrente de Junqueras. A costa de la Compañia. Y en dicha casa se hallarán otras de varios titulos escogidos.

[Forner y Segarra, Juan Pablo]

$\mathrm{s} / \mathrm{f}$ (a) Los aduladores. Tres manuscritos de la Biblioteca Histórica Municipal de Madrid. Sig. Tea 1-5-22. 1797 (Ms. A) y 1806 (Mss. B y C).

[Forner y Segarra, Juan Pablo]

s/f (b) Comedia Nueva: La escuela de la amistad, ó El Filósofo enamorado. Barcelona: Por Juan Francisco Piferrer Impresor de S. R. M. [s/f]; véndese en su Librería administrada por Juan Sellent, y en Madrid en la de Quiroga.

[Forner y Segarra, Juan Pablo]

$\mathrm{s} / \mathrm{f}$ (c) Comedia. El Filósofo Enamorado y Escuela de la amistad. Manuscrito del siglo XVIII, o principios del XIX, de setenta y ocho hojas, en cuarto, s. $1 ., \mathrm{s} / \mathrm{f}$, encuadernado en un tomo de varias obras manuscritas denominado en el lomo Comedias varias M. S., tomo 9. Conservado en la Biblioteca Nacional de España con la signatura Mss 18080. El tomo ha sido numerado, por hojas, no por páginas, correlativamente a lápiz. El manuscrito de El Filósofo ocupa las hojas 109-189. El tomo incluye las siguientes obras: La Ley Ejecutada, de Lope de Vega [hojas 1-66]; Lo que puede un empleo. Comedia en dos actos, en prosa. Año de 1812, de autor no especificado [hojas 67-108]; Comedia. La escuela de la amistad o El filósofo enamorado, de autor no especificado [Juan Pablo Forner] [hojas 
109-189a]; y Pítaco, de autor no especificado [Nicasio Álvarez de Cienfuegos] [hojas 189b-232].

Herrera Navarro, Jerónimo

1993 Catálogo de autores teatrales del siglo XVIII. Madrid: Fundación Universitaria Española.

Jiménez SALAs, María

1944 Vida y obras de Juan Pablo Forner y Segarra. Madrid: Consejo Superior de Investigaciones Científicas.

LOPEZ, François

1999 Juan Pablo Forner (1756-1797) y la crisis de la conciencia española. Traducción de Fernando Villaverde. Salamanca: Junta de Castilla y León.

Menéndez y Pelayo, Marcelino

1952 "Forner, Juan Pablo". En Biblioteca de traductores españoles. II, Domenech-Llodrá. Ed., Enrique Sánchez Reyes. Santander: Consejo Superior de Investigaciones Científicas, pp. 76-97.

Real Academia Española

1899 Diccionario de la lengua castellana por la Real Academia Española. Décimatercia edición. Madrid: Imprenta de los Sres. Hernando y compañía.

Ríos Carratalá, Juan Antonio

1987 “Destouches en España (1700-1835)”. Cuadernos de Traducción e Interpretación. 8/9, 257-265.

SÁiz, María Dolores

1990a "El primer diario español: Diario noticioso, curioso-erudito, comercial, público y económico". En su libro Historia del periodismo en España. 1. Los orígenes. El siglo XVIII. Madrid: Alianza (Alianza Universidad Textos), 2a ed., 122-125.

SÁrz, María Dolores

1990b "El Memorial literario". En su libro Historia del periodismo en España. 1. Los orígenes. El siglo XVIII. Madrid: Alianza (Alianza Universidad Textos), $2^{\mathrm{a}}$ ed., 168-169.

SAINZ y RodrígueZ, Pedro

1967 “Introducción”. En Exequias de la lengua castellana, de Juan Pablo Forner. Madrid: Espasa Calpe (Clásicos Castellanos, 66), I-XXXIX. 


\title{
APÉNDICE
}

La función de Los Aduladores en el Diario de Madrid

\author{
DIARIO DE MADRID \\ DEL DOMINGO 23 DE JULIO DE 1797. \\ Núm. 204. \\ P. 872.
}

Teatros. Hoy á las 8 en punto, en el Coliseo de los Caños del Peral , por la Compañia Italiana, se representa la Opera seria intitulada: la Cora de Quito, Vestal del Templo del Sol, con el bayle del Pastor Fido.

En el de la calle del Principe, por la Compañia del Sr. Francisco Ramos, se representa el Guzman, el Bayle de la Alemanda, dos saynetes, y una tonadilla; á las 5. La entrada de antes de anoche fue de 2190.

En el de la calle de la Cruz, por la Compañia del Sr. Luis Navarro, se representa la Comedia intitulada: del Rey abaxo ninguno, con saynete y una tonadilla; á las 5 .

CON PRIVILEGIO REAL.

En la Imprenta de Josef Franganillo, calle del Baño.

\author{
DIARIO DE MADRID \\ DEL LUNES 24 JULIO DE 1797. \\ Núm, 305. \\ P. 876.
}

Teatros. Hoy no hay Opera.

En el de la calle de la Cruz, por la Compañia del Sr. Luis Navarro, se representa una completa funcion teatral, compuesta de varias piezas, todas nuevas, cuyo órden será el siguiente. Despues de la Obertura con que dará principio la orqüestra; seguirá en un acto la Comedia intitulada los Aduladores: es del mismo ingenio que compuso el Filósofo Enamorado: concluida ésta, cantará una buena tonadilla á solo, titulada las Damas del nuevo Cuño, la Sra. Joaquina Arteaga: en seguida se 
representará por los Sres. Rita Luna, Manuel Garcia, Antonio Pinto, y Félix de Cubas, el Melodrama intitulado Armida y Reynaldo, segunda parte, escrito por D. Vicente Ramirez de Arellano: finalizada ésta, se cantará otra tonadilla por los Sres. Lorenza Correa, Bernardo Gil, y Mariano Querol: por fin de fiesta se executará el saynete intitulado los cinco Vecinos. Para que á esta plausible representacion no falte circunstancia que contribuya á hacerla mas vistosa y agradable, á mas del decoro de los Actores, y del Teatro, se han añadido unas Voleras, que baylará Josef Gonzalez, Baylarin del Teatro de los Reales Sitios, con el primor que es notorio: la Compañia espera merezca esta funcion las atenciones de un público tan benigno, especialmente la Sra. Rita Luna, en cuyo beneficio cede el producto de este dia; á las 8 . La entrada de ayer tarde fue de 1520: la de antes de anoche en el del Principe fue de 2133, y la de ayer tarde de 2327.

La tonadilla que cantará la Sra. Arteaga, se hallará de venta unida con su primera parte de la ciencia currutaca, que se ha cantado ya, á la entrada del Coliseo, y en la Libreria que está frente al mismo Coliseo.

Armida y Reynaldo, primera y segunda parte; se hallará en la libreria de Castillo, frente á S. Felipe el Real, en la de Cerro, calle de Cedaceros, y en su puesto, calle de Alcalá.

CON PRIVILEGIO REAL.

En la Imprenta de Joseph Franganillo, calle del Baño.

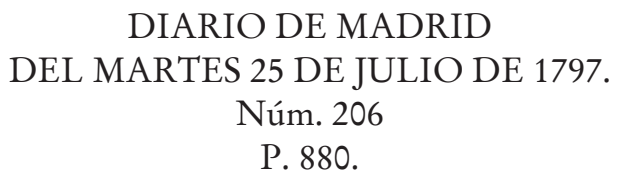

Teatros. Hoy á las 8 en punto, en el Coliseo de los Caños del Peral, por la Compañia Italiana, se representa la Opera seria intitulada: la Cora de Quito, Vestal del Templo del Sol, con el bayle del Pastor Fido.

En el de la calle del Principe, por la Compañia del Sr. Francisco Ramos, se representa la Comedia intitulada: el Vinatero de Madrid, con saynete y una tonadilla. Esta Compañia, deseosa de complacer en quanto sea posible á un público que tanto lo merece, ha concedido á un apasionado hacer el papel de primer Barba, el que suplica le disimulen sus defectos. 
En el de la calle de la Cruz, por la Compañia del Sr. Luis Navarro, se representa una completa funcion teatral, compuesta de varias piezas, todas nuevas, cuyo órden será el siguiente. Despues de la Obertura con que dará principio la orqüestra; seguirá en un acto la Comedia intitulada los Aduladores: es del mismo ingenio que compuso el Filósofo Enamorado: concluida ésta, cantará una buena tonadilla á solo, titulada las Damas del nuevo Cuño, la Sra. Joaquina Arteaga: en seguida se representará por los Sres. Rita Luna, Manuel Garcia, Antonio Pinto, y Félix de Cubas, el Melodrama intitulado Armida y Reynaldo, segunda parte, escrito por D. Vicente Ramirez de Are- llano: finalizada ésta, se cantará otra tonadilla por los Sres. Lorenza Correa, Bernardo Gil, y Mariano Querol: por fin de fiesta se executará el saynete intitulado los cinco Vecinos. Para que á esta plausible representacion no falte circunstancia que contribuya á hacerla mas vistosa y agradable, á mas del decoro de los Actores, y del Teatro, se han añadido unas Voleras, que baylará Josef Gonzalez, Baylarin del Teatro de los Reales Sitios, con el primor que es notorio; á las 5 .

\title{
CON PRIVILEGIO REAL.
}

En la Imprenta de Joseph Franganillo, calle del Baño.

\author{
DIARIO DE MADRID \\ DEL MIERCOLES 26 DE JULIO DE 1797. \\ Núm. 207. \\ P. 884.
}

En el de la calle de la Cruz, por la Compañia del Sr. Luis Navarro, se representa una completa funcion teatral, compuesta de varias piezas, todas nuevas, cuyo órden será el siguiente. Despues de la Obertura con que dará principio la orqüestra; seguirá en un acto la Comedia intitulada los Aduladores: es del mismo ingenio que compuso el Filósofo Enamorado: concluida ésta, cantará una buena tonadilla á solo, titulada las Damas del nuevo Cuño, la Sra. Joaquina Arteaga: en seguida se representará por los Sres. Rita Luna, Manuel Garcia, Antonio Pinto, y Félix de Cubas, el Melodrama intitulado Armida y Reynaldo, segunda parte, escrito por D. Vicente Ramirez de Are- llano: finalizada ésta, se cantará otra tonadilla por los Sres. Lorenza Correa, Bernardo Gil, y Mariano Querol: por fin de fiesta se executará el saynete intitulado 
los cinco Vecinos. Para que á esta plausible representacion no falte circunstancia que contribuya á hacerla mas vistosa y agradable, á mas del decoro de los Actores, y del Teatro, se han añadido unas Voleras, que baylará Josef Gonzalez, Baylarin del Teatro de los Reales Sitios, con el primor que es notorio; á las 5. La entrada de antes de anoche fue de 7381, y la de ayer tarde de 6265.

CON PRIVILEGIO REAL.

En la Imprenta de Joseph Franganillo, calle del Baño.

\author{
DIARIO DE MADRID \\ DEL JUEVES 27 DE JULIO DE 1797. \\ Núm. 208. P. 888.
}

En el de la calle de la Cruz, por la Compañia del Sr. Luis Navarro, se representa una completa funcion teatral, compuesta de varias piezas, todas nuevas, cuyo órden será el siguiente. Despues de la Obertura con que dará principio la orqüestra; seguirá en un acto la Comedia intitulada los Aduladores: es del mismo ingenio que compuso el Filósofo Enamorado: concluida ésta, cantará una buena tonadilla á solo, titulada las Damas del nuevo Cuño, la Sra. Joaquina Arteaga: en seguida se representará por los Sres. Rita Luna, Manuel Garcia, Antonio Pinto, y Félix de Cubas, el Melodrama intitulado Armida y Reynaldo, segunda parte, escrito por D. Vicente Ramirez de Are- llano: finalizada ésta, se cantará otra tonadilla por los Sres. Lorenza Correa, Bernardo Gil, y Mariano Querol: por fin de fiesta se executará el saynete intitulado los cinco Vecinos. Para que á esta plausible representacion no falte circunstancia que contribuya á hacerla mas vistosa y agradable, á mas del decoro de los Actores, y del Teatro, se han añadido unas Voleras, que baylará Josef Gonzalez, Baylarin del Teatro de los Reales Sitios, con el primor que es notorio; á las 8 . La entrada de ayer tarde fue de 5481, y la del Coliseo del Principe de 1049.

CON PRIVILEGIO REAL.

En la Imprenta de Joseph Franganillo, calle del Baño. 


\section{DIARIO DÉ MADRID \\ DEL VIERNES 28 DE JULIO DE 1737. \\ Núm. 209. \\ P. 892}

En el de la calle de la Cruz, por la Compañia del Sr. Luis Navarro, se representa una completa funcion teatral, compuesta de varias piezas, todas nuevas, cuyo órden será el siguiente. Despues de la Obertura con que dará principio la orqüestra; seguirá en un acto la Comedia intitulada los Aduladores: es del mismo ingenio que compuso el Filósofo Enamorado: concluida ésta cantará una buena tonadilla á solo, titu-lada las Damas del nuevo Cuño, la Sra. Joaquina Arteaga: en seguida se representará por los Sres. Rita Luna, Manuel, Garcia, Antonio Pinto, y Félix de Cubas, el Melodrama intitulado Armida y Reynaldo, segunda parte, escrito por D. Vicente Ramirez de Arellano: finalizada ésta, se cantará otra tonadilla por los Sres. Lorenza Correa, Bernardo Gil, y Mariano Querol: por fin de fiesta se ejecutará el saynete intitulado los cinco Vecinos. Para que á esta plausible representacion no falte circunstancia: que contribuya á hacerla mas vistosa y agradable, á mas del decoro de los Actores, y del Teatro, se han añadido unas Voleras, que baylará Josef Gonzalez, Baylarin del Teatro de los Reales Sitios, con el primor que es notorio; á las 8 .

CON PRIVILEGIO REAL.

En la Imprenta de Joseph Franganillo, calle del Baño.

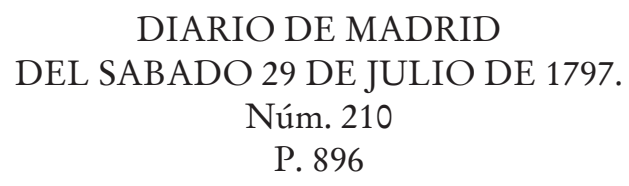

En el de la calle de la Cruz, por la Compañia del Sr. Luis Navarro, se representa una completa funcion teatral, compuesta de varias piezas, todas nuevas, cuyo órden será el siguiente. Despues de la Obertura con que dará principio la orqüestra; seguirá en un acto la Comedia intitulada los Aduladores: es del mismo ingenio que compuso el Filósofo Enamorado: concluida ésta cantará una buena tonadilla á solo, titu-lada las Damas del nuevo Cuño, la Sra. Joaquina Arteaga: en seguida se 
representará por los Sres. Rita Luna, Manuel, Garcia, Antonio Pinto, y Félix de Cubas, el Melodrama intitulado Armida y Reynaldo, segunda parte, escrito por D. Vicente Ramirez de Arellano: finalizada ésta, se cantará otra tonadilla por los Sres. Lorenza Correa, Bernardo Gil, y Mariano Querol: por fin de fiesta se ejecutará el saynete intitulado los cinco Vecinos. Para que á esta plausible representacion no falte circunstancia: que contribuya á hacerla mas vistosa y agradable, á mas del decoro de los Actores, y del Teatro, se han añadido unas Voleras, que baylará Josef Gonzalez, Baylarin del Teatro de los Reales Sitios, con el primor que es notorio; á las 8. La entrada de antes de anoche fué de 5811.

CON PRIVILEGIO REAL.

En la Imprenta de Joseph Franganillo, calle del Baño.

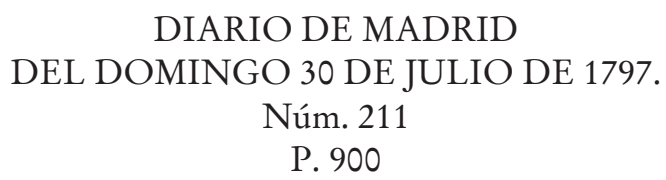

En el de la calle de la Cruz, por la Compañia del Sr. Luis Navarro, se representa una completa funcion teatral, compuesta de varias piezas, todas nuevas, cuyo órden será el siguiente. Despues de la Obertura con que dará principio la orqüestra; seguirá en un acto la Comedia intitulada los Aduladores: es del mismo ingenio que compuso el Filósofo Enamorado: concluida ésta, cantará una buena tonadilla á solo, titulada las Damas del nuevo Cuño, la Sra. Joaquina Arteaga: en seguida se representará por los Sres. Rita Luna, Manuel Garcia, Antonio Pinto, y Félix de Cubas, el Melodrama intitulado Armida y Reynaldo, segunda parte, escrito por D. Vicente Ramirez de Arellano: finalizada ésta, se cantará otra tonadilla por los Sres. Lorenza Correa, Bernardo Gil, y Mariano Querol: por fin de fiesta se executará e1 saynete intitulado los cinco Vecinos. Para que á esta plausible representacion no falte circunstancia que contribuya á hacerla mas vistosa y agradable, á mas del decoro de los Actores, y del Teatro, se han añadido unas Voleras, que baylará Josef Gonzalez, Baylarin del Teatro de los Reales Sitios, con el primor que es notorio; á las 5. La entrada de antes de anoche fué de 5403.

CON PRIVILEGIO REAL

En la Imprenta de Joseph Franganillo, calle del Baño. 


\title{
DIARIO DE MADRID \\ DEL LUNES 31 DE JULIO DE 1797. \\ Núm. 212 \\ P. 904.
}

En el de la calle de la Cruz, por la Compañia del Sr. Luis Navarro, se representa una completa funcion teatral, compuesta de varias piezas, todas nuevas, cuyo órden será el siguiente. Despues de la Obertura con que dará principio la orqüestra; seguirá en un acto la Comedia intitulada los Aduladores: es del mismo ingenio que compuso el Filósofo Enamorado: concluida ésta, cantará una buena tonadilla á solo, titulada las Damas del nuevo Cuño, la Sra. Joaquina Arteaga: en seguida se representará por los Sres. Rita Luna, Manuel Garcia, Antonio Pinto, y Félix de Cubas, el Melodrama intitulado Armida y Reynaldo, segunda parte, escrito por D. Vicente Ramirez de Arellano: finalizada ésta, se cantará otra tonadilla por los Sres. Lorenza Correa, Bernardo Gil, y Mariano Querol: por fin de fiesta se executará e1 saynete intitulado los cinco Vecinos. Para que á esta plausible representacion no falte circunstancia que contribuya á hacerla mas vistosa y agradable, á mas del decoro de los Actores, y del Teatro, se han añadido unas Voleras, que baylará Josef Gonzalez, Baylarin del Teatro de los Reales Sitios, con el primor que es notorio; á las 5 . La entrada de antes de anoche fué de 5724, la de ayer tarde de 5762, y la del Coliseo del Principe de 1421.

\section{CON PRIVILEGIO REAL}

En la Imprenta de Joseph Franganillo, calle del Baño.

\author{
DIARIO DE MADRID \\ DEL MARTES 1 DE AGOSTO DE 1797. \\ Núm. 213 \\ P. 908.
}

Teatros. Hoy no los hay segun costumbre.

CON PRIVILEGIO REAL

En la Imprenta de Joseph Franganillo, calle del Baño. 


\section{DIARIO DE MADRID \\ DEL MIERCOLES 2 DE AGOSTO DE 1797. \\ Núm. 214}

En el de la calle de la Cruz, por la Compañia del Sr. Luis Navarro, se representa una completa funcion teatral, compuesta de varias piezas, todas nuevas, cuyo órden será el siguiente. Despues de la Obertura con que dará principio la orqüestra; seguirá en un acto la Comedia intitulada los Aduladores: es del mismo ingenio que compuso el Filósofo Enamorado: concluida ésta, cantará una buena tonadilla á solo, titulada las Damas del nuevo Cuño, la Sra. Joaquina Arteaga: en seguida se representará por los Sres. Rita Luna, Manuel Garcia, Antonio Pinto, y Félix de Cubas, el Melodrama intitulado Armida y Reynaldo, segunda parte, escrito por D. Vicente Ramirez de Arellano: finalizada ésta, se cantará otra tonadilla por los Sres. Lorenza Correa, Bernardo Gil, y Mariano Querol: por fin de fiesta se executará e1 saynete intitulado los cinco Vecinos. Para que á esta plausible representacion no falte circunstancia que contribuya á hacerla mas vistosa y agradable, á mas del decoro de los Actores, y del Teatro, se han añadido unas Voleras, que baylará Josef Gonzalez, Baylarin del Teatro de los Reales Sitios, con el primor que es notorio; á las 7 1/2. La entrada de antes de anoche fue de 4254.

\section{CON PRIVILEGIO REAL}

En la Imprenta de Joseph Franganillo, calle del Baño.

\section{DIARIO DE MADRID}

DEL JUEVES 3 DE AGOSTO DE 1797.

Núm. 215.

P. 916.

En el de la calle de la Cruz, por la Compañia del Sr. Luis Navarro, se representa una completa funcion teatral, compuesta de varias piezas, todas nuevas, cuyo órden será el siguiente. Despues de la Obertura con que dará principio la orqüestra; seguirá en un acto la Comedia intitulada los Aduladores: es del mismo ingenio que compuso el Filósofo Enamorado: concluida ésta, cantará una buena tonadilla á solo, titulada las Damas del nuevo Cuño, la Sra. Joaquina Arteaga: en seguida se 
representará por los Sres. Rita Luna, Manuel Garcia, Antonio Pinto, y Félix de Cubas, el Melodrama intitulado Armida y Reynaldo, segunda parte, escrito por D. Vicente Ramirez de Arellano: finalizada ésta, se cantará otra tonadilla por los Sres. Lorenza Correa, Bernardo Gil, y Mariano Querol: por fin de fiesta se executará e1 saynete intitulado los cinco Vecinos. Para que á esta plausible representacion no falte circunstancia que contribuya á hacerla mas vistosa y agradable, á mas del decoro de los Actores, y del Teatro, se han añadido unas Voleras, que baylará Josef Gonzalez, Baylarin del Teatro de los Reales Sitios, con el primor que es notorio; á las 7 1/2.

CON PRIVILEGIO REAL

En la Imprenta de Joseph Franganillo, calle del Baño.

\section{DIARIO DE MADRID \\ DEL VIERNES 4 DE AGOSTO DE 1797. \\ Núm. 216. \\ P. 920.}

En el de la calle de la Cruz, por la Compañia del Sr. Luis Navarro, se representa una completa funcion teatral, compuesta de varias piezas, todas nuevas, cuyo órden será el siguiente. Despues de la Obertura con que dará principio la orqüestra; seguirá en un acto la Comedia intitulada los Aduladores: es del mismo ingenio que compuso el Filósofo Enamorado: concluida ésta, cantará una buena tonadilla á solo, titulada las Damas del nuevo Cuño, la Sra. Joaquina Arteaga: en seguida se representará por los Sres. Rita Luna, Manuel Garcia, Antonio Pinto, y Félix de Cubas, el Melodrama intitulado Armida y Reynaldo, segunda parte, escrito por D. Vicente Ramirez de Arellano: finalizada ésta, se cantará otra tonadilla por los Sres. Lorenza Correa, Bernardo Gil, y Mariano Querol: por fin de fiesta se executará e1 saynete intitulado los cinco Vecinos; á las 7 1/2. La entrada de antes de anoche fué de 3498.

\section{CON PRIVILEGIO REAL}

En la Imprenta de Joseph Franganillo, calle del Baño. 


\section{DIARIO DE MADRID \\ DEL VIERNES 5 DE AGOSTO DE 1797. \\ Núm. 217. \\ P. 924.}

En el de la calle de la Cruz, por la Compañia del Sr. Luis Navarro, se representa una completa funcion teatral, compuesta de varias piezas, todas nuevas, cuyo órden será el siguiente. Despues de la Obertura con que dará principio la orqüestra; seguirá en un acto la Comedia intitulada los Aduladores: es del mismo ingenio que compuso el Filósofo Enamorado: concluida ésta, cantará una buena tonadilla á solo, titulada las Damas del nuevo Cuño, la Sra. Joaquina Arteaga: en seguida se representará por los Sres. Rita Luna, Manuel Garcia, Antonio Pinto, y Félix de Cubas, el Melodrama intitulado Armida y Reynaldo, segunda parte, escrito por D. Vicente Ramirez de Arellano: finalizada ésta, se cantará otra tonadilla por los Sres. Lorenza Correa, Bernardo Gil, y Mariano Querol: por fin de fiesta se executará e1 saynete intitulado los cinco Vecinos; á las 7 1/2. La entrada de antes de anoche fué de 3178.

CON PRIVILEGIO REAL

En la Imprenta de Joseph Franganillo, calle del Baño.

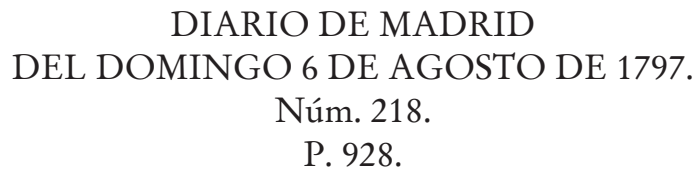

En el de la calle de la Cruz, por la Compañia del Sr. Luis Navarro, se representa una completa funcion teatral, compuesta de varias piezas, todas nuevas, cuyo órden será el siguiente. Despues de la Obertura con que dará principio la orqüestra; seguirá en un acto la Comedia intitulada los Aduladores: es del mismo ingenio que compuso el Filósofo Enamorado: concluida ésta, cantará una buena tonadilla á solo, titulada las Damas del nuevo Cuño, la Sra. Joaquina Arteaga: en seguida se representará por los Sres. Rita Luna, Manuel Garcia, Antonio Pinto, y Félix de Cubas, el Melodrama intitulado Armida y Reynaldo, segunda parte, escrito por D. Vicente Ramirez de Arellano: finalizada ésta, se cantará otra tonadilla por los Sres. Lorenza Correa, Bernardo Gil, y 
Mariano Querol: por fin de fiesta se executará e1 saynete intitulado los cinco Vecinos; á las 5. La entrada de antes de anoche fué de 2522.

CON PRIVILEGIO REAL

En la Imprenta de Joseph Franganillo, calle del Baño.

Los días 7, 8, y 9 de agosto, en la sección de Teatros del Diario de Madrid, no se incluye la referencia a las funciones del Teatro de la Cruz. Tal vez por permanecer esos días cerrado por estar previsto, en los días siguientes, una variación en las obras que se iban a montar, y por estar la compañía titular, la de Luis Navarro, como vimos, dedicadas a los ensayos para poder efectuar un cambio en la cartelera.

\section{DIARIO DE MADRID \\ DEL LUNES 7 DE AGOSTO DE 1797.}

Núm. 219.

P. 932.

Teatros. Hoy no hay Opera.

En el de la calle del Principe por la Compañía del Sr. Francisco Ramos se representa la funcion siguiente: se dará principio con una introducion, seguirá una tonadilla á tres, cantada por los Señores Vicenta Laporta, Miguél Garrido y Vicente Camas; continuará un Melodrama intitulado: la Noche triste de Troya, y se concluirá la funcion con un fin de fiesta, el que finalizará con un pequeño bayle; todo nuevo, de Teatro; á las 7 1/2. La entrada de ayer tarde fue de 2597; la de antes de anoche en el de la Cruz de 2256, y la de ayer tarde de 3190.

Este melodrama se hallará en la Libreria de Castillo, frente á San Felipe el Real, en la de Cerro, calle de Cedaceros, y en su puesto calle de Alcalá real.

\section{CON PRIVILEGIO REAL}

En la Imprenta de Joseph Franganillo, calle del Baño. 


\title{
DIARIO DE MADRID \\ DEL JUEVES 10 DE AGOSTO DE 1797. \\ Núm. 222. \\ P. 944.
}

En el de la calle de la Cruz, por la Compañia del Sr. Luis Navarro, se representa la Comedia intitulada: los Amantes de Teruel; con sainete y una tonadilla; á las 5.

En el Diario del viernes 11 de agosto de 1797, núm. 223, p. 952, se informa que la entrada de esta función fue “en el de la Cruz de 1701”, p. 952.

En el En el Diario del sábado 12 de agosto de 1797, n²23, p. 956, no aparece información sobre el Teatro de la Cruz. El domingo 13 sí, (n ${ }^{\circ} 225$, p. 960), y sigue escenificándose Los amantes de Teruel, con 2294 espectadores, según el Diario de lunes 14, n 226, p. 968.

En el En el Diario del martes 15 de agosto de 1797, n²27, p. 972, se informa del cambio de comedia en el Teatro de la Cruz.

Revisados todos los números del Diario de Madrid aparecidos en el mes de agosto del 1797, en contra de la noticia que transmite el Memorial literario, no se realizaron, por esos días, representaciones de Los aduladores en el Teatro del Príncipe de la Corte, solo en el Teatro de la Cruz.

\author{
DIARIO DÉ MADRID \\ DEL LUNES 10 DE FEBRERO DE 1806. \\ $\mathrm{N}^{\circ} 41$ \\ P. 184.
}

En el teatro de los Caños del Peral, á las 5 de la tarde, se representará por la Compañía destinada al teatro del Príncipe la comedia titulada El Carbonero de Londres, con tonadilla y sainete. La entrada de ayer tarde fué de 4.703 


\section{DIARIO DÉ MADRID \\ DEL MÁRTES 11 DE FEBRERO DE 1806. \\ $\mathrm{N}^{\circ} 42$ \\ P. 188.}

En el teatro de los Caños del Peral, á las 5 de la tarde, se executará por la Compañía destinada al teatro del Príncipe una divertida miscelánea de la forma siguiente: se dará principio con una pieza moral, en un acto, titulada Los Aduladores, seguirá una tonadilla á tres, y se dará fin con un gracioso saynete nuevo, nombrado La Fiesta de Toros de Juan Tuerto, en el que se lidiarán quatro de estos animales con la mayor naturalidad. La entrada de ayer tarde fué de 2,697.

CON REAL PRIVILEGIO

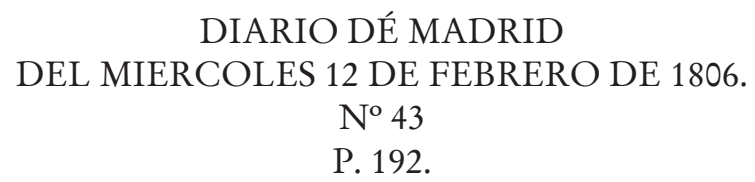

En el teatro de los Caños del Peral, á las 5 de la tarde, se executará por la Compañía destinada al teatro del Príncipe una divertida miscelánea de la forma siguiente: se dará principio con una pieza moral, en un acto, titulada Los Aduladores, seguirá una tonadilla á tres, y se dará fin con un gracioso saynete nuevo, nombrado La Fiesta de Toros de Juan Tuerto, en el que se lidiarán quatro de estos animales con la mayor naturalidad. La entrada de ayer tarde fué de 12,554.

CON REAL PRIVILEGIO

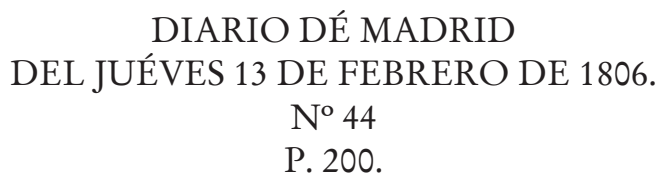

En el teatro de los Caños del Peral, á las 5 de la tarde, se executará por la Compañía destinada al teatro del Príncipe una divertida miscelánea de la forma siguiente: se dará principio con una pieza moral, en 
un acto, titulada Los Aduladores, seguirá una tonadilla á tres, y se dará fin con un gracioso saynete nuevo, nombrado La Fiesta de Toros de Juan Tuerto, en el que se lidiarán quatro de estos animales con la mayor naturalidad. La entrada de ayer tarde fué de 11,743.

CON REAL PRIVILEGIO

\author{
DIARIO DÉ MADRID \\ DEL VIERNES 14 DE FEBRERO DE 1806. \\ $\mathrm{N}^{\circ} 45$ \\ P. 204.
}

En el teatro de los Caños del Peral, á las 5 de la tarde, se executará por la Compañía destinada al teatro del Príncipe: sedará principio con el saynete del Payo de la Carta: en el que cantará el Sr. Pedro Cubas, las seguidillas del Gallinero, se cantará la tonadilla á tres Los Maestros de la Raboso, y se dara fin con un gracioso saynete nuevo, nombrado $L a$ Fiesta de Toros de Juan Tuerto, en el que se lidiarán quatro de estos animales con la mayor naturalidad. La entrada de ayer tarde fué de 9,841.

CON REAL PRIVILEGIO

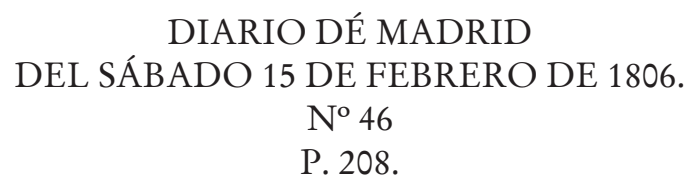

En el teatro de los Caños del Peral, á las 5 de la tarde, se executará por la Compañía destinada al teatro del Principe la funcion siguiente; se dará principio con el saynete del Payo de la Carta, en el que cantará el Sr. Pedro Cubas las seguidillas del Gallinero, seguirá una tonadilla á tres titulada Los Maestros de la Raboso, y se dará fin con un gracioso saynete nuevo, nombrado La Fiesta de Toros de Juan Tuerto, en el que se lidiarán quatro de estos animales con la mayor naturalidad. La entrada de ayer tarde fué de 9,174.

CON REAL PRIVILEGIO 


\section{DIARIO DÉ MADRID \\ DEL DOMINGO 16 DE FEBRERO DE 1806. \\ $\mathrm{N}^{\circ} 47$ \\ P. 212.}

En el teatro de los Caños del Perai, á las 4 1/2 de la tarde, se executará por la Compañia destinada al teatro del Principe la función siguiente: se dará principio con el saynete del Payo de la Carta, en el que cantará el Sr. Pedro Cubas las seguidillas del Gallinero, seguirá una tonadilla á tres titulada Los Maestros de la Raboso, y se dará fin coa un gracioso saynete nuevo, nombrado La Fiesta de Toros de Juan Tuerto, en el que se lidiarán quatro de estos animales con la mayor naturalidad. La entrada de ayer tarde fué de 9,148.

A las 8 de la noche se executará la misma función, con sola la diferencia de que en lugar del primer saynete se representará el titulado Los tres Huéspedes burlados.

Nota. Se advierte de nuevo, á fin de evitar equivocaciones, que los villetes de la funcion de la noche son los diarios, y, tienen impreso el dia, y los de la tarde no le tienen, y se distinguen ademas con las palabras Por la tarde.

\section{CON REAL PRIVILEGIO}

Revisados todos los números de Diario de Madrid correspondientes al mes febrero de 1806, y los correspondientes a la primera semana de marzo de 1806, no se hallan más datos sobre Los aduladores.

Recepción: 08/05/2020

Aceptación: 12/07/2020 